\title{
Struggling to Get through the Bitterness of Life - An Experience of Women with Spinal Cord Injury in the First 5 Years after Injury - A Content Analysis Study
}

\author{
Adel Mir ${ }^{1}$, Mozhgan Rahnama², Mahin Naderi Far ${ }^{3}$, Mahin Badakhsh", Elahm Mir5, Amin Mir ${ }^{6}$ \\ ${ }^{1}$ Student Research Committee, Faculty of Nursing and Midwifery, Zabol University of Medical \\ Sciences, Zabol, Iran. ${ }^{2}$ Department of Nursing, Zabol University of Medical Sciences, Zabol, Iran. \\ ${ }^{3}$ Department of Nursing, Zabol University of Medical Sciences, Zabol, Iran. ${ }^{4}$ Department of \\ Midwifery, Zabol University of Medical Sciences, Zabol, Iran. ${ }^{5}$ Zabol University of Medical Sciences, \\ Zabol, Iran. ${ }^{6}$ Zabol University of Medical Sciences, Zabol, Iran.
}

\section{ABSTRACT}

\section{BACKGROUND}

Spinal cord injury (SCI) causes widespread disorders in the sensory, motor, mental, and sexual systems. This injury imposes a significant burden on the healthcare system during the first 5 years. Previous relevant researches have rarely focused on SCI in women. Quantitative research methods lack the capacity and capability to address such issues. Therefore, we wanted to evaluate the experiences of SCI women in the first 5 years of injury using content analysis method.

\section{METHODS}

This was a qualitative study with conventional content analysis approach. Purposeful sampling was performed on 6 female SCI patients. Data was collected through indepth semi-structured interviews. The recorded interviews were transcribed verbatim. Content analysis was used to reduce the data, name the data, obtain analytical codes, and finally detect the theme.

\section{RESULTS}

Analysis of the data collected from the participants resulted in the extraction of 4 themes and 2 sub-themes including, bitter memory of physical sufferings, emotional bitterness of a numb body, struggle to keep on living, and paradoxical forces of life (inhibitors and facilitators).

\section{CONCLUSIONS}

Investigating the experiences of SCI women in the first 5 years of injury showed that SCI causes these women to suffer from various physical sufferings, and experience many bitter feelings despite physical numbness. However, despite these bitter experiences, these women are struggling to keep on living, but there are facilitators and inhibitors and these women are struggling to control these inhibitors by relying on facilitators and to get through these bitter events by their own efforts. Therefore, struggle to get through the bitterness of life can be considered as the essence of the experience of SCI women in the first 5 years after injury in the present study.

\section{KEY WORDS}

Women, Spinal Cord Injury, First 5 Years after Injury, Content Analysis
Corresponding Author: Mozhgan Rahnama,

Associate Professor, Department of Nursing, Zabol University of Medical Sciences, Zabol, Iran.

E-mail:morahnama0@gmail.com

DOI: $10.14260 /$ jemds/2020/479

How to Cite This Article: Mir A, Rahnama M, Far MN, et al. Struggling to get through the bitterness of life- an experience of women with spinal cord injury in the first 5 years after injury- a content analysis study. J. Evolution Med. Dent. Sci. 2020;9(31):2202-2207, DOI: 10.14260/jemds/2020/479

Submission 29-02-2020,

Peer Review 12-06-2020,

Acceptance 18-06-2020,

Published 03-08-2020.

Copyright (c) 2020 Adel Mir et al. This is an open access article distributed under Creative Commons Attribution License [Attribution 4.0 International (CC BY 4.0)] 


\section{BACKGROUND}

Spinal cord injuries (SCIs) are among the most damaging injuries a person can experience. (1) 0 n average, SCI affects 1 to 2 people per million populations in the world every year.(2) According to the national spinal cord injury statistical center (NCCISC), there are approximately 27000 people with SCI in the United States, and approximately 3 new SCI cases occur annually year.(3) Increasing life span and life expectancy of SCI patients means living with disability for longer time, which is associated with the occurrence of problems and the need to accept responsibilities that negatively affect their lives ${ }^{(4)}$ and cause widespread disturbances in the sensory, motor, psychological, and sexual system.(5) In this regard, Robinson et al. (2014) confirm the prevalence of depression in SCI women.(6) Besides, SCI women have been found to have specific sexual concerns and problems.(7) S Akhavan Amjadi (2017) indicated that SCI women needed sexual rehabilitation.(8),(9) SCI is an experience that not only changes the life path of a SCI person, but also their spouses, parents, and children.(2) In addition, physical-motor disabilities cause a great deal of damage in terms of production and social costs.(10),(11) Activities that seem simple and easy for healthy people are difficult for such people. These people face numerous problems every day such as financial problems, lack of social support, and health problems.(12),(13)

Overall, considering the scarcity of relevant studies in this area on SCI women $(7,8)$ and the fact that SCI imposes a significant burden on the healthcare system in the first 5 years after injury(14),(15) on the one hand, and since examining the experiences and knowledge of the issues that SCI persons face while getting through this crisis is essential for proper organization of conditions(16),(17) and the quantitative research methods lack capacity and capability needed to address such issues, on the other hand, therefore, it is necessary to carry out a detailed study using a qualitative approach to describe the phenomenon based on the participants' experiences in the form of conversations and expression of feelings. Therefore, the aim of the present study was to explain the experiences of SCI women in the first 5 years after injury using content analysis method. It is hoped that this study can provide guidance for implementing healthcare strategies for the treatment team by providing a clear picture of human experiences.

\section{METHODS}

This was a qualitative study with conventional content analysis approach. We investigated the experiences of six SCI women in the first 5 after injury using the conventional content analysis approach. The focus of phenomenology is to describe how individuals experience a specific phenomenon characterizing the lived experience of a phenomenon by gathering detailed narrative data from a small number of participants. The goal is to generate a deep understanding and the meaning of a particular phenomenon from the perspective of the individual. These SCI women had a medical case at Welfare and Rehabilitation Center of Zabul County. Samples were selected using purposeful sampling. These participants were SCI patients in the first 5 years of injury, Persianspeakers and volunteers. Exclusion criteria included hearing or speech problems and unwillingness or inability to participate in the study. Data collection was carried out the researcher through referring to the rehabilitation and welfare center and the patients' home based on previous coordination and obtaining their permission. Initially, the objective of the research was explained to them, and then the sampling continued until reaching data saturation. The criterion for reaching data saturation included lack of access to new concepts and codes in subsequent interviews. The method of data collection included semi-structured in-depth interviews using open-ended questions, including, "Talk about your experiences after spinal cord injury? What has changed in your life after spinal cord injury?" During the interview, the researcher helped the participants share their experiences without directing the conversation. Probing questions were also used if necessary. The interviews were conducted in a quiet environment. Each interview lasted 45-60 minutes in one or two sessions depending on the condition and patience of the participants. All interviews were recorded, typed verbatim, coded, and analysed by the researcher immediately. In fact, data analysis was carried out simultaneously and continuously with data collection. Data analysis was carried out using conventional content analysis approach. At the beginning, each interview was read carefully for achieving initial understanding, important statements were underlined, and recorded using codes (initial coding). The participants' own words and implicit codes (researcher's perceptions of the words) were used for initial coding. Then, conceptually similar codes were summarized and then classified into categories and subcategories to clarify meaning. Data analysis was performed according to the steps described by Graneheim \& Lundman.(9),(18) To ensure credibility, the coded texts of interviews were given to the participants to confirm their concordance with their experiences and provide corrections in some cases. In order to meet the dependability criterion, the researcher consulted with experts and colleagues in the research project regarding resulting codes and concepts. Several colleagues were also asked to code some parts of the transcript of the interviews and then review the coding agreement. In order to ensure the transferability of the findings, attempts were made to enrol patients with different demographic characteristics and experiences, and the researcher evaluates all aspects of behaviours, events and lived experiences. Conformability of findings was also verified by the researcher's rich description of all stages of the research, while the details of the research were carefully documented to allow the evaluation of external observers. The ethical considerations respected in the present study included, including obtaining an introduction letter, obtaining informed consent from the interviewees for recording the interviews, confidentiality, and the right to withdraw.

\section{RESULTS}

Demographic characteristics of the participants are presented in Table 1. Analysis of the data collected from the participants resulted in the extraction of 4 themes and 2 sub-themes including, 1. Bitter memory of physical sufferings, 2. Emotional 
bitterness of a numb body 3 . Struggle to keep on living and 4 Paradoxical forces of life (life inhibitors and life facilitators).

\begin{tabular}{|c|c|c|c|c|c|c|c|}
\hline & 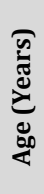 & $\frac{n}{\stackrel{n}{\tilde{n}}}$ & 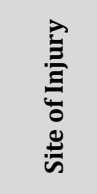 & 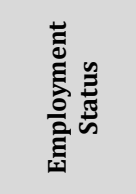 & 亗总 & 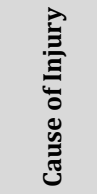 & 苍. \\
\hline 1 & 34 & Single & Thoracic & Unemployed & 2 & Slipping & Diploma \\
\hline 2 & 26 & Married & Lumbar & Unemployed & 5 & Accident & Middle school \\
\hline 3 & 42 & Married & Lumbar & Unemployed & 3 & Accident & Diploma \\
\hline 4 & 17 & Single & Lumbar & Unemployed & 5 & Accident & Diploma \\
\hline 5 & 30 & Married & Thoracic & Unemployed & 5 & Accident & Diploma \\
\hline 6 & 35 & Married & Cervical & Unemployed & 3 & Accident & Middle school \\
\hline \multicolumn{8}{|c|}{ Table 1. Demographic Characteristics of SCI Women } \\
\hline
\end{tabular}

\section{Bitter Memory of Physical Sufferings}

The experiences of SCI women showed that they had bitter memories of their physical sufferings. Most of them had suffered SCI in a car accident, and experienced limb numbness, pain, constipation, bed sores, hospitalization, and prolonged immobility, and various infections. As one of the participating women described her limb numbness as follows:

"Following SCI, I have no sensation from the waist down in other members of my body. If they're cut, I won't notice anything at all" (participant No. 1).

Also, another female participant talked about her constipation as one of the defecation problems:

"I have had severe constipation since I had SCI, I have bowel movement every three to four days, and sometimes after a week when I have to use my fingers to remove the stool.

\section{Emotional Bitterness of a Numb Body}

Following SCI, these women, despite physical numbness, become very sensitive in the emotional dimension and have varied and had experienced bitter feelings such as hopelessness, tired of living life, loss of wishes, nervousness, family and children suffering, sympathy of others, hatred of wheelchair dependence, lack of self-esteem and selfworthlessness, financial dependency on others, being neglected by others, being a burden to others, helplessness, rejected, embracement of dependence on wheelchair and others, disgusting wheelchair use, reaching a therapeutic dead end, the being infamous, being uncertain of their health status, being punished by God due to their sins. At the same time, they had lost the sense of sexual pleasure. One participant described the reason for understanding his futility due to being neglected by others:

"One day, my uncle came to our home and was never talking to me, he was just talking to my sister and I was very upset about it" (participant no. 1)

And another female participant described feeling rejected by her husband:

"After being paralyzed following an accident, my living conditions have become very difficult because my husband has left me after the accident" (participant no. 2)

Another participant who experienced a lack of sexual pleasure said:

"I do not enjoy sex with my husband since I suffered from SCI" (participant no. 3)

\section{Struggle to Keep on Living}

Investigating of experiences of SCI showed that they were struggling to keep on living despite their physical sufferings and bitter feelings. They also ignored people's pitiful views and attended the society, attained independence in doing their personal affairs, gradually moved using walking aids, overcame preventing immobility- complications using physiotherapy and waving mattresses, gained control over their stool and urine incontinence, showed patience in the face of problems, showed self-control, and kept calm. In this regard, one of the affected women described, gaining independence in her personal affairs as follows:

"Now, I'm somewhat able to do my personal affairs 5 years after the injury" (participant no. 4)

And another female participant described gaining control over faecal incontinence with sensitivity to defecation symptoms:

"It's been 5 years since my SCI. I experience signs when I have bowel movement that include sweating, stomach-ache, and being under a lot of pressure, I wear diapers at the same time" (participant no. 5)

\section{Paradoxical Forces of Life}

According to the experiences of SCI women, while struggling to keep on living, they were confronted with two categories of paradoxical forces, life facilitators, including physical and psychological care of nurses, proper care from family and friends, meeting medical expenses by fathers, improved morale by seeing peers and attending their gathering, gaining hope from relatives, physiotherapy, receiving training from the medical team, relying on religious beliefs, hoping for healing or treatment, receiving care and attention from husbands and not being abandoned by them, and providing financial well-being services that facilitate conditions for them to continue living. In this regard, one of the women described the role of physiotherapy in gaining her mobility:

"When I discharged from hospital, I was on the bed for three months, then I went to physiotherapy and was gradually able to use wheelchairs and walkers to move" (participant no. 3)

And another SCI woman said about the role of her husband in the care process:

"Whenever I have defecation sign, I have to use diapers, my husband certainly changes my diaper, if he is at home. I only wear dipper myself once during the SCI course" (participant no. 5).

Furthermore, inhibitors including financial problems, the inability to purchase equipment such as waving mattresses, catheters and sanitary pads, unemployment and inability to pay for medical care, inadequate care and treatment, such as late diagnosis of vertebral injury and delay in surgery, and inefficient individual reactions to SCI such as crying, denial of treatment, and escaping people's views, which make conditions worse for these women to keep on living. In this regard, one of the participating women said about staggering medical expenses:

"My dad is an employee at the Department of Fisheries. My medical expenses are too expensive, but we have no choice and we have gotten along, the welfare does not provide sufficient financial support and all costs are imposed on us" (participant no. 4). 
And another woman described her inability to buy the needed equipment as follows:

"I used to frequently use a urine catheter after placing it in betadine long ago because I had no money to buy a new urine catheter, consequently, I got a severe urinary tract infection" (participant no. 3).

\section{DISCUSSION}

The present study revealed that SCI women, in addition to physical numbness, are highly sensitive emotionally and have had experienced various bitter feelings such as hopelessness, tired of living life, loss of wishes, nervousness, family and children suffering, sympathy of others, hatred of wheelchair dependence, lack of self-esteem and self-worthlessness, financial dependency on others, being neglected by others, futility, being a burden to others, helplessness, rejected, embracement of dependence on wheelchair and others, disgusting wheelchair use, reaching a therapeutic dead end, being infamous, being uncertain of their health status, being punished by God due to their sins. Other studies have investigated SCI patients' perception of some feelings such as anger, sins, loneliness, hopelessness, dependence, and futility.(11,16),(17,19,20)

The women of the present study were embarrassed due to their dependence on others. In a qualitative study on patients with physical disabilities, Pashaei Sabet et al. also referred to independence as one of the themes.(13),(21) Regarding the loneliness of people with disabilities, Zahirinia (2011) also writes that loneliness is more prevalent in people with disabilities as a consequence of their disability.(22) Confirming the feelings of futility and being neglected by others, Pentland et al. (2002) showed in a study on SCI women that they felt isolated, neglected, or forgotten by healthcare providers.(14),(7) Atadokht et al. (2014) showed that people with physicalmotor disabilities were significantly different from normal people in terms of stress, anxiety, and depression. He writes that people with disabilities have weaker social interactions, lower self-esteem and self-confidence than others, and experience greater psychological stress than others.(17),(23) Similarly, in a qualitative study on lived experiences of SCI people, Fuzeini et al. (2019) referred to psychological and social effects of SCI as one of the themes.(4),(10)

While acknowledging the SCI-induced suffering of family, spouse and children, Mohammadi (2016) emphasizes that SCI person experiences nightmare due to immobility and loss of ability to perform a large number of activities. Experiencing such bitter change in life affects not only the individual him/herself but also all members of the family, including spouse, parents, sisters, brothers, and children.(18) In a qualitative study, Nikbakht - Nasrabadi et al. (2017) referred to the need for support in a context filled with limitations as the essence of experiences of spouses of SCI clients and stated that their spouses faced numerous limitations and challenges and family empowerment was suggested(19),(24) because caregivers face distressing conditions due to long hours of care, social isolation, high emotional stress, depression, and economic problems. (18),(4)
The results of the present study also showed that some SCI women had lost sexual pleasure despite having sex with their husbands. Some women were reluctant to make such relationship. Similarly, in a study on factors affecting sexual satisfaction in SCI women, Otero-Villaverde (2015) concludes that numbness in the genital area I considered as a factor affecting sexual satisfaction.(5),(12) However, in their review of sexual health and reproductive function of women following spinal cord injury, Curtis et al. (2017) suggested that sexual pleasure, orgasm, and pregnancy were possible for these women.(20),(25) Singh et al. (2015) also writes that the importance and interest in sex does not change in SCI women, and sexual problems are one of the major concerns of these patients.(7),(16) This difference may be due to physical, psychological, and cultural issues. In a study on the sexual health needs of SCI women, Akhavanamjadi (2017) also highlighted the need for sexual counseling to promote the sexual health of these women.(8),(9)

Examination of experiences of SCI women showed that they were struggling to keep on living despite their physical sufferings and bitter feelings. Therefore, they ignored people's pitiful views and attended the society, attained independence in doing their personal affairs, gradually moved using walking aids, overcame preventing immobility- complications using physiotherapy and waving mattresses, gained control over their stool and urine incontinence, showed patience in the face of problems, showed self-control, and kept calm. In a qualitative study, Baba Mohammadi et al. (2011) showed that SCI patients made efforts to adapt themselves with conditions after SCI by reducing their dependence and attaining selfcare.(1) Tagaki (2015) also showed in a qualitative study that SCI patients attempted to live as healthy individuals and find positive aspects of their lives.(21),(26) The majority of SCI patients found themselves to be happy (Dagan et al. (2016)(22),(27) Also, study participants reported that SCI is associated with negative outcomes as well as positive outcomes such as increased skills and increased spirituality in life (Kennedy et al. 2013).(23),(28) All of these results are indicative of these patients' desire to keep on living and are consistent with the present study.

However, the present study revealed that SCI women struggled to survive while struggling with two paradoxical forces, i.e., life inhibitors and facilitators. All SCI women referred to economic problems as an inhibitor for keep on living, which is rooted in the high cost of treatment. Nikkhah \& Fadaei (2016) also identified economic needs as one of the needs of people with disabilities and emphasized their other needs, including employment, housing, and allowances.(24) Inefficient Individual reactions to injury such as crying, denial of treatment, and escaping people's views were also among other inhibitors. In justifying the non-constructive reactions of SCI patients, Berari \& Ghafari (215) write, disability exists not only in the body of people with disabilities but also in their mindsets and attitudes so that they experience a change in their lifestyles, loss of relationships, and social isolation as a result of their disability.(25) Ebadollahi et al. (2012) also suggested people with disabilities are stigmatized due to views and attitudes of society and healthy people, which in turn indicates their inadequacy and inability, causing a sense of futility and self-worthlessness. This unnecessary pity can also lead to feelings of inadequacy, dependency, inferiority or even anger. 
Based on the experiences of SCI women, support of families and social support organizations have been identified as a facilitator of keep on living, which is consistent with a study by Mohammadi (2016) who concluded and recommended that families caring for these patients should be supported and supervised by social and health support organizations.(18),(4)

In addition to identifying the social dimension of the needs of people with disabilities, Nikhah \& Fadaei (2016) emphasized that SCI patients need to have insurance services and the presence of appropriate staff in welfare organizations and other disability-related organizations.(24), The influential supportive role of the family in the Nikbakhtnasrabadi et al.' study has also been identified as a facilitator of the recovery of SCI patients. (26) Hosseini Golafshani et al. (2013) also referred to excellent and smart relatives as one of the themes identified in their study. They emphasized that relatives play an important and influential role in shaping one's attitude to life after injury especially in the first years after injury.(111,(20) The results of Atadokht et al.'s study (2014) also showed that levels of stress, anxiety, and depression in people with physicalmotor disabilities were significantly related with the support of important individuals, friends, and family. (17)(23) The results of studies by Khanjani et al. (2019) and Rahmaninia et al. (2017) referred to proper support from the relatives as an important facilitator in adapting these SCI patients to new conditions. $(27,28)$

\section{CONCLUSIONS}

Investigating experiences of SCI women in first 5 years after injury revealed that these women suffered from various physical sufferings, and experience numerous bitter feelings in addition to their body numbness. However, despite these bitter experiences, these women are struggling to keep on living, but there are facilitators and inhibitors in this regard, and they are struggling to control these barriers by relying on facilitators and to get through these bitter events by their own efforts. Therefore, struggle to get through the bitterness of life can be considered as the essence of the experience of SCI women in the first 5 years after injury in the present study.

This article is the result of a research of Master of Internal Surgery, Faculty of Nursing, Zabol University of Medical Sciences (IR.ZBMU.REC.1397.169). The authors express their gratitude to Zabol University of Medical Sciences, the participating patients and all those who assisted us with this research.

Financial or Other Competing Interests: None.

\section{REFERENCES}

[1] Babamohamadi H, Negarandeh R, Dehghan-Nayeri N. Coping strategies used by people with spinal cord injury: a qualitative study. Spinal Cord 2011;49(7):832-7.

[2] Abdolahi M. Evaluation of quality of life in patients with spinal cord injury following the Bam earthquake in 2003.
Iranian Journal of Rehabilitation Research in Nursing 2016;3(2):1-7.

[3] Dillaway HE, Lysack CL. Most of them are amateurs: women with spinal cord injury experience the lack of education and training among medical providers while seeking gynecological care. Disability Studies Quarterly 2015;35(3).

[4] Fuseini AG, Aniteye P, Alhassan A. Beyond the diagnosis: lived experiences of persons with spinal cord injury in a selected town in Ghana. Neurology Research International 2019;2019:1-10.

[5] Otero-Villaverde S, Ferreiro-Velasco M, Montoto-Marques A, et al. Sexual satisfaction in women with spinal cord injuries. Spinal Cord 2015;53(7):557-60.

[6] Robinson-Whelen S, Taylor HB, Hughes RB, et al. Depression and depression treatment in women with spinal cord injury. Top Spinal Cord Inj Rehabil 2014;20(1):23-31.

[7] Singh R, Sharma SC. Sexuality and women with spinal cord injury. Sexuality and Disability 2005;23(1):21-33.

[8] Amjadi MA, Simbar M, Hosseini SA, et al. The sexual health needs of women with spinal cord injury: a qualitative study. Sexuality and Disability 2017;35(3):313-30.

[9] Graneheim UH, Lundman B. Qualitative content analysis in nursing research: concepts, procedures and measures to achieve trustworthiness. Nurse Educ Today 2004;24(2):105-12.

[10] Tolabi Z, Ghanbari F. Veterans' life experiences: a phenomenological study. J Qual Res Health Sci 2015;4(3):266-79.

[11] Hosseni GSZ, Abedi HA, Ahmadi F. Reflection on the experiences of disabled people: the society as a cause of growth or barrier. J Qual Res Health Sci 2013;2(3):24860.

[12] Khodayarian M, Jalalpour S, Hosseini H. The survey of quality of life of spinal cord injured people in Yazd in 2014. Journal Military Caring Sciences 2015;1(2):88-98.

[13] Sabet FP, Tabrizi KN, Khankeh HR, et al. Rehabilitation needs of patients with physical disabilities due to traffic accidents for returning to the community: a qualitative study. Iranian Journal of Rehabilitation Research in Nursing 2014;1(1):74-87.

[14] Dryden DM, Saunders LD, Rowe BH, et al. Utilization of health services following spinal cord injury: a 6-year follow-up study. Spinal Cord 2004;42(9):513-25.

[15] Pentland W, Walker J, Minnes P, et al. Women with spinal cord injury and the impact of aging. Spinal Cord 2002;40(8):374-87.

[16] Noe BB, Bjerrum M, Angel S. The beginning of a new life following traumatic spinal cord injury-patient's experiences one month post-discharge. Int J Phys Med Rehabil 2015;3:1.

[17] Atadokht A, Jokar KAN, Hoseini KST, et al. The role of perceived social support in predicting psychological disorders in people with physical disability and its comparison with normal subjects. J Rehabil 2014;15(3):27-34.

[18] Mohammadi S, Roshanzadeh M. The effect of educational intervention based on Orem self-care model on family caregiver's burden of patients with spinal cord injuries. Rehabilitation 2016;17(1). 
[19] Nikbakht A, Gomarverdi S, Bastami A, et al. Spouses' experiences of living with patients with spinal cord injuries: a phenomenological study. Iranian Journal of Nursing Research 2017;12(3):24-35.

[20] Courtois F, Alexander M, McLain ABJ. Women's sexual health and reproductive function after SCI. Top Spinal Cord Inj Rehabil 2017;23(1):20-30.

[21] Tagaki M. Long-term experiences of men with spinal cord injuries in Japan: a qualitative study. Forum: Qualitative Social Research 2015;16(2).

[22] Duggan C, Wilson C, DiPonio L, et al. Resilience and happiness after spinal cord injury: a qualitative study. Top Spinal Cord Inj Rehabil 2016;22(2):99-110.

[23] Kennedy P, Lude P, Elfström M, et al. Perceptions of gain following spinal cord injury: a qualitative analysis. Top Spinal Cord Inj Rehabil 2013;19(3):202-10.
[24] Nikkhah H, Fadaei S. The study of economic, sociocultural and psychological needs of the disabled people. Journal of Hormozgan Cultural Research Review 2016;5(10):29-45.

[25] Barari B, Ghaffari M. Mental health of physically disabled persons compare to the normal people: investigation based on the psychopathology and positive psychology approaches. Middle Eastern Journal of Disability Studies 2015;5:281-8.

[26] Nikbakht A, Bastami A, Tabrizi KN, et al. Exploring homebased rehabilitation in traumatic spinal cord injury patients: a qualitative study. Iranian Journal of Nursing Research 2017;11(6):32-41.

[27] Khanjani MS, Khankeh HR, Younesi SJ, et al. The main factors affecting the acceptance and adaptation with spinal cord injury: a qualitative study. J Rehabil 2019;19(4):276-91.

[28] Rasa AR, Hosseini SA, Haghgoo H, et al. Aspects related to resilience in people with spinal cord injury. Arch Rehabil 2017;17(4):350-9. 